\title{
Effect of pressure-assisted heat treatment on photoluminescence emission of $\alpha-\mathrm{Bi}_{2} \mathrm{O}_{3}$ needles
}

\author{
Samara Schmidt, ${ }^{\dagger}$ Evaldo T. Kubaski ${ }^{*}$, Diogo P. Volanti, ${ }^{\S}$ Thiago Sequinel, ॥ \\ Vinicius Danilo N. Bezzon, ${ }^{\dagger}$ Armando Beltrán, ${ }^{\mid}$Sergio M. Tebcherani, ${ }^{\perp}$ and José A. Varela $*, \dagger$ \\ $\dagger$ Department of Physical Chemistry, UNESP - Institute of Chemistry, \\ 14800-060 Araraquara, SP, Brazil \\ $\$$ Department of Materials Engineering, State University of Ponta Grossa, \\ 84030-900 Ponta Grossa, PR, Brazil \\ $\S^{\S}$ Department of Chemistry and Environmental Sciences, UNESP - IBILCE, \\ 15054-000 São José do Rio Preto, SP, Brazil \\ " Department of Production Engineering, Federal University of Technology - Paraná, \\ 84016-210 Ponta Grossa, PR, Brazil \\ ${ }^{\perp}$ Department of Chemistry, State University of Ponta Grossa, \\ 84030-900 Ponta Grossa, PR, Brazil \\ ' Departament de Química Física i Analítica, Universitat Jaume I, \\ Campus del Riu Sec, E-12071 Castelló de la Plana, Spain
}




\section{ABSTRACT}

Materials with high photoluminescence (PL) intensity can potentially be used in optical and electronic devices. Although the PL properties of bismuth (III) oxide with a monoclinic crystal structure $\left(\alpha-\mathrm{Bi}_{2} \mathrm{O}_{3}\right)$ have been explored in the last few years, methods of increasing PL emission intensity and information relating PL emission to structural defects are scarce. This research evaluated the effect of a pressure-assisted heat treatment (PAHT) on the PL properties of $\alpha$ $\mathrm{Bi}_{2} \mathrm{O}_{3}$ with a needle morphology, which was synthesized by a microwave-assisted hydrothermal (MAH) method. The pressure-assisted heat treatment caused an angular increase between the $\left[\mathrm{BiO}_{6}\right]-\left[\mathrm{BiO}_{6}\right]$ clusters of $\alpha-\mathrm{Bi}_{2} \mathrm{O}_{3}$, resulting in a significant increase in the PL emission intensity. The Raman and XPS spectra also showed that the $\alpha-\mathrm{Bi}_{2} \mathrm{O}_{3}$ PL emissions in the lowenergy region (below about $2.1 \mathrm{eV}$ ) are attributed to oxygen vacancies that form defect donor states. The experimental results are in good agreement with first-principles total-energy calculations that were carried out within the periodic density-functional-theory (DFT) framework.

\section{KEYWORDS}

Bismuth(III) oxide; photoluminescent properties; $\left[\mathrm{BiO}_{6}\right]-\left[\mathrm{BiO}_{6}\right]$ clusters.

\section{INTRODUCTION}

Recently, bismuth (III) oxide $\left(\mathrm{Bi}_{2} \mathrm{O}_{3}\right)$ has become a promising candidate for a variety of applications because of its properties such as a variable band gap (from 2.0 to $3.96 \mathrm{eV}$ ), photoconductivity, photoluminescence, high refractive index, dielectric permittivity, and oxygen 
conductivity. ${ }^{1-2}$ In spite of the great technological interest in $\mathrm{Bi}_{2} \mathrm{O}_{3}$, some of its optical and electronic properties are not well known. One of the problems associated with $\mathrm{Bi}_{2} \mathrm{O}_{3}$ studies is the existence of four main polymorphic phases that exhibit distinct properties: $\alpha$ (monoclinic), $\beta$ (tetragonal), $\gamma$ (body-centered cubic), and $\delta$ (face-centered cubic). The stable phase at room temperature is $\alpha-\mathrm{Bi}_{2} \mathrm{O}_{3}$, while the high-temperature phase is $\delta-\mathrm{Bi}_{2} \mathrm{O}_{3}$ that stabilizes around $730^{\circ} \mathrm{C}$ and melts at $824^{\circ} \mathrm{C}$. The $\gamma-\mathrm{Bi}_{2} \mathrm{O}_{3}$ and $\beta-\mathrm{Bi}_{2} \mathrm{O}_{3}$ phases form at temperatures below $639^{\circ} \mathrm{C}$ and $650^{\circ} \mathrm{C}$, respectively. The formation of $\beta-\mathrm{Bi}_{2} \mathrm{O}_{3}$ depends on impurities and oxide reaction conditions. Both the $\gamma$ and $\beta$ phases are metastable and can be obtained by controlled cooling during the process of crystal growth. ${ }^{2-3}$ For example, Harwig and Gerards ${ }^{4}$ showed the formation $\gamma$ and $\beta$ phases using cooling rates of 0.1 and $33^{\circ} \mathrm{C} \mathrm{min}^{-1}$. They also provide a detailed study on the formation of metastable phases of $\mathrm{Bi}_{2} \mathrm{O}_{3}$ at different cooling rates.

Depending on the method of preparation, $\alpha-\mathrm{Bi}_{2} \mathrm{O}_{3}$ can contain traces of a secondary phase, which can contribute to the bulk properties of the oxide because its polymorphs have a distinct nature. In some cases, the presence of a secondary phase impedes adequate control of the properties of $\mathrm{Bi}_{2} \mathrm{O}_{3}$ and makes the technological application of this oxide difficult. ${ }^{5}$ Therefore, the evaluation of the phases that are present and their possible transitions are important topics related to the potential uses of this material. ${ }^{6}$ Furthermore, the combination of X-ray powder diffraction (XRD) and the Rietveld Method (RM) ${ }^{7}$ allows evaluation of the possible structural variations in $\alpha-\mathrm{Bi}_{2} \mathrm{O}_{3}$.

The photoluminescence (PL) behavior of $\mathrm{Bi}_{2} \mathrm{O}_{3}$ has been investigated in the last few years because of the different optical applications of this oxide. ${ }^{6,8-9}$ Most results are explained by the fact that the band gap values depend on different phases or on the particle size of nanostructures. 10-11 The PL spectra of $\alpha-\mathrm{Bi}_{2} \mathrm{O}_{3}$ microcrystals generally show a band at $2.8 \mathrm{eV}$ attributed to a 
recombination between valence and conduction bands, and a band at $2.98 \mathrm{eV}$, which corresponds to surface state interactions. $\alpha-\mathrm{Bi}_{2} \mathrm{O}_{3}$ nanoparticles show a band of PL emission at $3.12 \mathrm{eV} \cdot{ }^{6,9}$ For $\alpha-\mathrm{Bi}_{2} \mathrm{O}_{3}$ ceramics, the PL emission consisted of three bands with maxima at 2.70, 2.40, and 1.97 $\mathrm{eV}$; these bands were associated with complexes containing closely packed bismuth and oxygen in the crystal structure. ${ }^{11-12}$ Unlike for other oxides of technological interest, information regarding $\mathrm{PL}$ emission in $\alpha-\mathrm{Bi}_{2} \mathrm{O}_{3}$ related to native defects or other types of defects is still scarce ${ }^{13}$ Furthermore, low-energy PL emissions (below about $2.1 \mathrm{eV}$ ) are explained in terms of oxygen defects and bismuth oxidation states. ${ }^{6,11,14}$ Materials with increased PL properties are of interest, and obtaining a higher PL emission at a low synthesis temperature is important to decrease costs in several electronic and optical devices.

Pressure-assisted heat treatment (PAHT) was successfully used to prepare calcium copper titanate $\left(\mathrm{CaCu}_{3} \mathrm{Ti}_{4} \mathrm{O}_{12}, \mathrm{CCTO}\right){ }^{15}$ and zinc oxide $(\mathrm{ZnO})$ thin films. ${ }^{16}$ In CCTO films, PAHT caused a decrease in the band gap, moving the PL emission to a lower energy region. ${ }^{15}$ Similarly, in $\mathrm{ZnO}$ films, PAHT promoted a significant change in the level of defects, shifting the PL emission from green to orange-yellow. ${ }^{16}$

PAHT caused significant changes in the PL properties of CCTO ${ }^{15}$ and $\mathrm{ZnO}{ }^{16}$ thin films, and it is hypothesized that a similar influence could be found in bulk $\alpha-\mathrm{Bi}_{2} \mathrm{O}_{3}$. Based on these facts, this study aims to investigate the effect of PAHT on the PL properties of $\alpha-\mathrm{Bi}_{2} \mathrm{O}_{3}$ needles synthesized by the microwave-assisted hydrothermal (MAH) method 


\section{MATERIALS AND METHODS}

\section{Reactants}

The reactants used in the experiments were bismuth (III) nitrate pentahydrate $\left(\mathrm{Bi}\left(\mathrm{NO}_{3}\right)_{3} \cdot 5 \mathrm{H}_{2} \mathrm{O}\right.$, Sigma-Aldrich, 99.99\%), potassium hydroxide (KOH, J. T. Baker, 87.0\%), nitric acid $\left(\mathrm{HNO}_{3}\right.$, Sigma-Aldrich, 65\%), and polyethylene glycol (PEG-300, Sigma-Aldrich).

\section{Microwave-assisted hydrothermal (MAH) synthesis of $\alpha-\mathrm{Bi}_{2} \mathrm{O}_{3}$}

The bismuth solution was prepared by dissolving $2.19 \mathrm{~g}$ of $\mathrm{Bi}\left(\mathrm{NO}_{3}\right)_{3} \cdot 5 \mathrm{H}_{2} \mathrm{O}$ in $40 \mathrm{~mL} \mathrm{HNO}_{3}$ with continuous stirring. After complete dissolution, $2 \mathrm{~mL}$ of PEG-300 were added and the solution was stirred for $10 \mathrm{~min}$. Then, a $\mathrm{KOH}$ solution $\left(6 \mathrm{~mol} \cdot \mathrm{L}^{-1}\right)$ was added dropwise with stirring until $\mathrm{pH}=14$. The solution was stirred for $5 \mathrm{~min}$ and the formation of a gelatinous white precipitate was observed. The solution and the precipitate were transferred to a polytetrafluoroethylene reactor, and were placed in the $\mathrm{MAH}$ system for $30 \mathrm{~min}$ at $80^{\circ} \mathrm{C}$ with a heating rate of $10^{\circ} \mathrm{C} \cdot \mathrm{min}^{-1}$. After cooling the reactor to room temperature, the formation of a yellow precipitate was observed. The resulting material was washed six times with distilled water until $\mathrm{pH} \sim 7$. After centrifugation, the powder was dried in petri dishes at $70^{\circ} \mathrm{C}$ for $24 \mathrm{~h}$. Finally, the powder was calcined at $400^{\circ} \mathrm{C}$ for $1 \mathrm{~h}$ at a heating rate of $10^{\circ} \mathrm{C} \cdot \mathrm{min}^{-1}$ to eliminate any trace of PEG-300, which could be adsorbed on the samples. Samples obtained by this route were labeled $\alpha-\mathrm{Bi}_{2} \mathrm{O}_{3}-\mathrm{MAH}$.

\section{Pressure-assisted heat treatment (PAHT)}

Samples of $\alpha-\mathrm{Bi}_{2} \mathrm{O}_{3}-\mathrm{MAH}$ were heat treated under an air pressure of $2 \mathrm{MPa}$ at $120^{\circ} \mathrm{C}$ for $48 \mathrm{~h}$ to evaluate the effect of PAHT on the PL properties of $\alpha-\mathrm{Bi}_{2} \mathrm{O}_{3}$. Samples that underwent the pressure-assisted heat treatment were labeled $\alpha-\mathrm{Bi}_{2} \mathrm{O}_{3}-\mathrm{PAHT}$.

\section{Sample characterization}


Powder samples of $\alpha-\mathrm{Bi}_{2} \mathrm{O}_{3}-\mathrm{MAH}$ and $\alpha-\mathrm{Bi}_{2} \mathrm{O}_{3}-\mathrm{PAHT}$ were characterized by X-ray diffraction (XRD) at room temperature using a Rigaku Ultima IV diffractometer with $\mathrm{CuK} \alpha$ radiation, a goniometer radius of $185 \mathrm{~mm}$, a curved graphite monochromator, and a scintillation counter operating in the reflection mode with the Bragg-Brentano geometry. The divergence, scattering, and receiving slits were $0.5^{\circ}, 0.5^{\circ}$, and $0.3 \mathrm{~mm}$, respectively. Data were collected over the $2 \theta$ measuring range from $15^{\circ}$ to $90^{\circ}$ in the continuous scan mode $(1 \% \mathrm{~min})$.

Refinements were carried out by the Rietveld method using Fundamental Parameters (FP) implemented in the software Topas Academic V. 5. ${ }^{17}$ FPs were used to describe the peak profile by executing the convolutions of functions in reference to the contribution of wavelength distribution, instrumental parameters of the geometry used, and sample physical properties. A silicon standard sample was used to obtain the instrumental broadening, which was corrected using FPs. ${ }^{18}$ The background was adjusted using a Chebyshev polynomial function implemented in the software with four terms for correction. Lattice parameters and crystallite size were refined, and a spherical harmonics preferred orientation correction with eight terms was applied. Malmros ${ }^{19}$ reported the crystalline structure used in these refinements. The values of the crystallite size were calculated using a macro implemented in the software Topas Academic V. 5; 17 the macro considers the integrated peak intensity to estimate the mean value of the crystallite size. After the refinements, CIF files were created for each sample to simulate material structures in the software Diamond V. 3.2e. ${ }^{20}$ In addition, interatomic distances with uncertainties were calculated using the program Bond_Str. ${ }^{21}$

Morphological features of the samples were analyzed by field emission scanning electron microscopy (FESEM) using a Jeol 7500F instrument. Samples were dispersed in isopropyl alcohol with the assistance of an ultrasound bath. A drop of this suspension was deposited on a 
conductive silicon substrate, and the sample was dried at room temperature before FESEM analysis.

PL measurements of $\alpha-\mathrm{Bi}_{2} \mathrm{O}_{3}-\mathrm{MAH}$ and $\alpha-\mathrm{Bi}_{2} \mathrm{O}_{3}-\mathrm{PAHT}$ were performed with a Thermo Jarrel Ash Monospec $(27 \mathrm{~cm})$ monochromator coupled to an R955 Hamamatsu photomultiplier using a krypton ion laser (Coherent Innova 200) operating at a wavelength of $350 \mathrm{~nm}$ and $60 \mathrm{~mW}$ output power. The PL spectra were obtained as a function of wavelength and were converted to photon energy $(\mathrm{eV})$, and each PL intensity was multiplied by $\lambda^{2}$ to obtain the corrected intensity. ${ }^{22-23}$ Deconvolution analyses of PL spectra were performed using the Peakfit Program (version $4.05) ;{ }^{24}$ a Gaussian function was used to adjust the PL bands to determine peak positions and their corresponding areas. The least number of Gaussian emissions necessary to obtain the best fit in plots was used, and each parameter was fitted for each spectrum independently. The contribution of each PL band was estimated in terms of its area that was expressed in percentage. Ultraviolet-visible (UV-vis) absorption spectra were obtained using a Varian Cary 50 spectrophotometer to determine the band gap of $\alpha-\mathrm{Bi}_{2} \mathrm{O}_{3}-\mathrm{MAH}$ and $\alpha-\mathrm{Bi}_{2} \mathrm{O}_{3}-\mathrm{PAHT}$; the band gap was estimated using the Kubelka-Munk method. ${ }^{25}$ All these characterizations were performed at room temperature.

Raman spectroscopy was used to estimate short and medium range order, crystal potential fluctuations, and local atomic arrangement of samples, and as an auxiliary technique to investigate changes in crystal symmetry that can be caused by PAHT. Raman spectra were obtained by a spectrometer equipped with a Kimmon set of mirrors. Measurements were obtained for solid samples at room temperature using a He-Cd laser with a wavelength of 514 $\mathrm{nm}$. Scans were obtained over the range of 100 to $600 \mathrm{~cm}^{-1}$. 
The chemical states of the elements in $\alpha-\mathrm{Bi}_{2} \mathrm{O}_{3}-\mathrm{MAH}$ and $\alpha-\mathrm{Bi}_{2} \mathrm{O}_{3}-\mathrm{PAHT}$ were characterized by X-Ray Photoelectron Spectroscopy (XPS) using a UNI-SPECS UHV System commercial spectrometer at a pressure below $5 \times 10^{-7} \mathrm{~Pa}$. The $\mathrm{Mg} \mathrm{K \alpha}$ line (energy of $1253.6 \mathrm{eV}$ ) was used as the ionization source and the pass energy of the analyzer was set to $10 \mathrm{eV}$. The inelastic background of the high-resolution spectra $\mathrm{Bi} 4 \mathrm{f}, \mathrm{C} 1 \mathrm{~s}$, and $\mathrm{O} 1 \mathrm{~s}$ orbitals was subtracted using the Shirley method. ${ }^{26}$ The spectral binding-energy scale was corrected using the hydrocarbon component fixed at $285.0 \mathrm{eV}$. The width at half height varied between 1.2 and $2.1 \mathrm{eV}$, and the peak position were determined with a precision of $\pm 0.1 \mathrm{eV}$.

\section{Theoretical calculation}

First-principles total-energy calculations were carried out within the periodic densityfunctional-theory (DFT) framework using CRYSTAL14 program package. ${ }^{27}$ The Kohn-Sham equations have been solved by means of exchange-correlation functionals in the generalized gradient approximation (GGA) developed for solids by Perdew, Burke and Ernzerhof (PBESol). ${ }^{28}$ The $\mathrm{Bi}$ and $\mathrm{O}$ centers have been described in the scheme [PS]-41G* and 6-31G*, respectively, where [PS] stands for the non-relativistic effective core pseudo-potential. Both the [PS]-41G* and 6-31G* basis sets can be found at http://www.crystal.unito.it/basis-sets.php. We have optimized geometrical parameters and internal positions at both ambient pressure and $2 \mathrm{MPa}$ (EXTPRESS option).

\section{RESULTS AND DISCUSSION}

Both $\alpha-\mathrm{Bi}_{2} \mathrm{O}_{3}-\mathrm{MAH}$ and $\alpha-\mathrm{Bi}_{2} \mathrm{O}_{3}-\mathrm{PAHT}$ samples showed a pure $\alpha-\mathrm{Bi}_{2} \mathrm{O}_{3}$ phase, as determined from the XRD data and Rietveld plots that are depicted in Figure 1. Table 1 shows the values of the lattice parameters and atomic positions obtained after the refinements. This table also 
presents the agreement factors of the refinements. Although these numeric criteria are slightly high, Young ${ }^{29}$ reported that it is also necessary to consider graphical criteria. Consequently, a careful evaluation of Figures 1(a) and (b) indicates an adequate adjustment between the observed and calculated profiles.
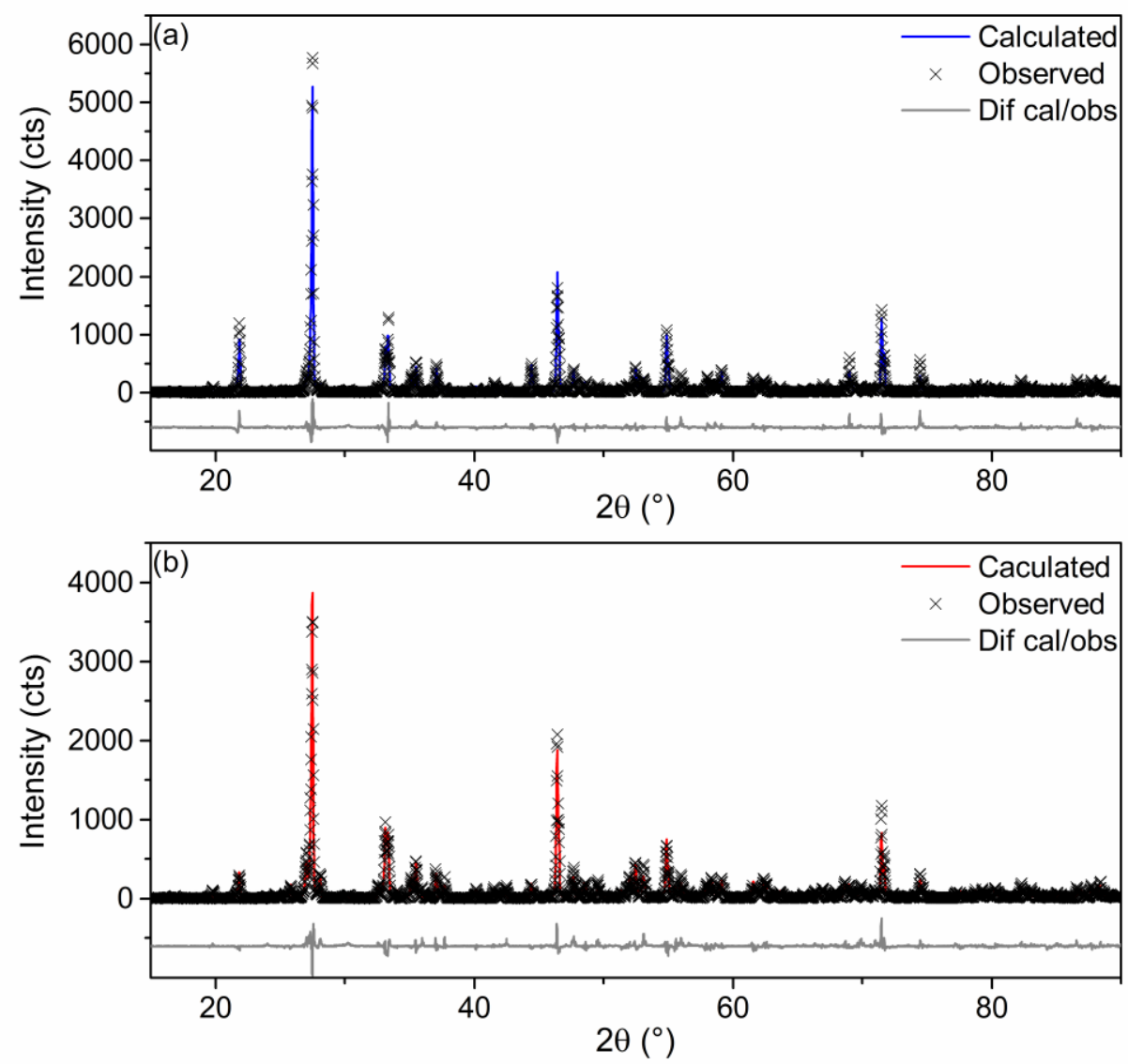

Figure 1. Rietveld plots of the samples. (a) $\alpha-\mathrm{Bi}_{2} \mathrm{O}_{3}-\mathrm{MAH}$, (b) $\alpha-\mathrm{Bi}_{2} \mathrm{O}_{3}-\mathrm{PAHT}$

The comparison between the results of the two samples shows a slight variation in atomic position, especially for the oxygen sites. This variation is probably because of the synthesis method used for sample $\alpha-\mathrm{Bi}_{2} \mathrm{O}_{3}-\mathrm{MAH}$. PAHT virtually caused no alteration in the lattice parameters of the samples; the cell volume was the same for both samples. In addition, another parameter that showed no variation was the crystallite size because both samples showed the same order of magnitude. 
Table 1. Refined structural parameters and the respective agreement factors of the refinement.

\begin{tabular}{|c|c|c|c|}
\hline \multicolumn{4}{|c|}{ Space group $P 2_{1} / c$} \\
\hline \multicolumn{2}{|c|}{$\alpha-\mathrm{Bi}_{2} \mathrm{O}_{3}-\mathrm{MAH}$} & \multicolumn{2}{|c|}{$\alpha-\mathrm{Bi}_{2} \mathrm{O}_{3}-\mathrm{PAHT}$} \\
\hline \multicolumn{2}{|c|}{ Lattice parameters } & \multicolumn{2}{|c|}{ Lattice parameters } \\
\hline \multicolumn{2}{|c|}{$a=5.8480(6) \AA$} & \multicolumn{2}{|c|}{$\mathrm{a}=5.8484(3) \AA$} \\
\hline \multicolumn{2}{|l|}{$\mathrm{b}=8.1690(10) \AA$} & \multicolumn{2}{|l|}{$\mathrm{b}=8.1687(5) \AA$} \\
\hline \multicolumn{2}{|l|}{$c=7.5131(8) \AA$} & \multicolumn{2}{|l|}{$\mathrm{c}=7.5133(4) \AA$} \\
\hline \multicolumn{2}{|l|}{$\alpha=90^{\circ}$} & \multicolumn{2}{|l|}{$\alpha=90^{\circ}$} \\
\hline \multicolumn{2}{|l|}{$\beta=112.970(7)^{\circ}$} & \multicolumn{2}{|l|}{$\beta=112.992(4)^{\circ}$} \\
\hline \multicolumn{2}{|c|}{ Volume: $330.46 \AA^{3}$} & \multicolumn{2}{|c|}{ Volume: $330.42 \AA^{3}$} \\
\hline \multicolumn{2}{|c|}{ Atomic positions } & \multicolumn{2}{|c|}{ Atomic positions } \\
\hline Bil site & $\mathrm{Bi} 2$ site & Bi1 site & $\mathrm{Bi} 2$ site \\
\hline$x=0.5244(8)$ & $x=0.0410(7)$ & $x=0.5246(7)$ & $x=0.0410(6)$ \\
\hline$y=0.18332(17)$ & $y=0.04082(18)$ & $\mathrm{y}=0.1819(2)$ & $\mathrm{y}=0.0423(2)$ \\
\hline $\mathrm{z}=0.3573(6)$ & $\mathrm{z}=0.7799(8)$ & $\mathrm{z}=0.3584(5)$ & $z=0.7781(6)$ \\
\hline $\mathrm{Beq}^{*}=0.40(4) \AA^{2}$ & $\mathrm{Beq}^{*}=0.92(4) \AA^{2}$ & $\mathrm{Beq}^{*}=0.70(6) \AA^{2}$ & $\mathrm{Beq}^{*}=0.83(7) \AA^{2}$ \\
\hline O1 site & $\mathrm{O} 2$ site & O1 site & $\mathrm{O} 2$ site \\
\hline $\mathrm{x}=0.818(9)$ & $x=0.260(3)$ & $x=0.815(8)$ & $x=0.261(9)$ \\
\hline$y=0.303(2)$ & $\mathrm{y}=0.044(3)$ & $y=0.297(2)$ & $y=0.048(2)$ \\
\hline $\mathrm{z}=0.768(10)$ & $\mathrm{z}=0.133(10)$ & $\mathrm{z}=0.751(8)$ & $\mathrm{z}=0.174(7)$ \\
\hline $\mathrm{O} 3$ site & & $\mathrm{O} 3$ site & \\
\hline$x=0.294(9)$ & & $\mathrm{x}=0.329(9)$ & \\
\hline$y=0.033(3)$ & & $y=0.015(3)$ & \\
\hline $\mathrm{z}=0.448(9)$ & & $\mathrm{z}=0.513(7)$ & \\
\hline \multicolumn{2}{|c|}{ Agreement factors } & \multicolumn{2}{|c|}{ Agreement factors } \\
\hline \multicolumn{2}{|c|}{$\mathrm{R}_{\text {Bragg }}=7.35 \%$} & \multicolumn{2}{|c|}{$\mathrm{R}_{\mathrm{Bragg}}=8.00 \%$} \\
\hline \multicolumn{2}{|c|}{$\mathrm{R}_{\mathrm{wp}}=22.60 \%$} & \multicolumn{2}{|c|}{$\mathrm{R}_{\mathrm{wp}}=22.52 \%$} \\
\hline \multicolumn{2}{|c|}{$\mathrm{R}_{\exp }=11.99 \%$} & \multicolumn{2}{|c|}{$\mathrm{R}_{\exp }=12.25 \%$} \\
\hline \multirow{2}{*}{\multicolumn{2}{|c|}{$\begin{array}{c}\mathrm{S}=1.88 \\
\text { Crystallite size }(\mathbf{n m})\end{array}$}} & \multirow{2}{*}{\multicolumn{2}{|c|}{$\begin{array}{c}\mathrm{S}=1.84 \\
\text { Crystallite size (nm) }\end{array}$}} \\
\hline & & & \\
\hline \multicolumn{2}{|c|}{$\begin{array}{c}\text { Crystallite size (nm) } \\
137(5)\end{array}$} & & (4) \\
\hline
\end{tabular}

\footnotetext{
*Beq $=$ temperature factor. Obs: The temperature factors for oxygen atoms were constrained during the refinement following the values presented by Malmros. ${ }^{19}$
} 
The Diamond software ${ }^{20}$ allowed simulation of the material structure, the coordination of the $\mathrm{Bi}$ and $\mathrm{O}$ atoms, and measurement of the angle between the coordination polyhedra. The simulations showed changes in the relative distance of separation between atoms when both $\alpha-\mathrm{Bi}_{2} \mathrm{O}_{3}-\mathrm{MAH}$ and $\alpha-\mathrm{Bi}_{2} \mathrm{O}_{3}-\mathrm{PAHT}$ are compared (Table 2), although the coordination of the polyhedra had been preserved. $\alpha-\mathrm{Bi}_{2} \mathrm{O}_{3}-\mathrm{PAHT}$ shows that the relative angles between clusters $\left[\mathrm{BiO}_{6}\right]-\left[\mathrm{BiO}_{6}\right]$ were greater than in $\alpha-\mathrm{Bi}_{2} \mathrm{O}_{3}-\mathrm{MAH}$ (Figure 2).

Table 2. Interatomic distances $(\AA)$ with uncertainties between $\mathrm{Bi}$ and $\mathrm{O}$ atoms in the $\alpha-\mathrm{Bi}_{2} \mathrm{O}_{3}$ simulated structures.

\begin{tabular}{|c|c|c|c|c|c|}
\hline \multicolumn{3}{|c|}{$\alpha-\mathrm{Bi}_{2} \mathrm{O}_{3}-M A H$} & \multicolumn{3}{|c|}{$\alpha-\mathrm{Bi}_{2} \mathrm{O}_{3}-\mathrm{PAHT}$} \\
\hline \multirow{6}{*}{$\mathrm{B} 1$} & $\mathrm{O} 1$ & $3.05(6)$ & \multirow{6}{*}{ B1 } & $\mathrm{O} 1$ & $2.93(5)$ \\
\hline & $\mathrm{O} 1$ & $2.08(7)$ & & $\mathrm{O} 1$ & $2.15(6)$ \\
\hline & $\mathrm{O} 2$ & $2.12(4)$ & & $\mathrm{O} 2$ & $1.96(4)$ \\
\hline & $\mathrm{O} 2$ & $3.19(3)$ & & $\mathrm{O} 2$ & $3.29(3)$ \\
\hline & $\mathrm{O} 3$ & $2.12(6)$ & & $\mathrm{O} 3$ & $2.36(5)$ \\
\hline & $\mathrm{O} 3$ & $2.28(4)$ & & $\mathrm{O} 3$ & $1.90(3)$ \\
\hline \multirow{6}{*}{$\mathrm{B} 2$} & $\mathrm{O} 1$ & $2.49(3)$ & \multirow{6}{*}{$\mathrm{B} 2$} & $\mathrm{O} 1$ & $2.43(3)$ \\
\hline & $\mathrm{O} 1$ & $2.19(4)$ & & $\mathrm{O} 1$ & $2.22(3)$ \\
\hline & $\mathrm{O} 2$ & $2.45(7)$ & & $\mathrm{O} 2$ & $2.74(5)$ \\
\hline & $\mathrm{O} 2$ & $2.21(5)$ & & $\mathrm{O} 2$ & $2.07(6)$ \\
\hline & $\mathrm{O} 3$ & $3.36(7)$ & & $\mathrm{O} 3$ & $3.08(6)$ \\
\hline & $\mathrm{O} 3$ & $2.12(4)$ & & $\mathrm{O} 3$ & $2.45(4)$ \\
\hline
\end{tabular}

Figure 3 depicts the needle-like morphological features of $\alpha-\mathrm{Bi}_{2} \mathrm{O}_{3}-\mathrm{MAH}$ and $\alpha-\mathrm{Bi}_{2} \mathrm{O}_{3}-\mathrm{PAHT}$ analyzed by FESEM. It was found that pure $\alpha-\mathrm{Bi}_{2} \mathrm{O}_{3}$ needles could be obtained for MAH using 
alkaline $\mathrm{KOH}$ solution $\left(6 \mathrm{~mol} \cdot \mathrm{L}^{-1}\right)$. The as-prepared $\alpha-\mathrm{Bi}_{2} \mathrm{O}_{3}$ needles are non-agglomerated particles; length, and aspect ratio of needles are in the ranges $41-13 \mu \mathrm{m}$ and $14-9$, respectively (Figure 3(a)). Furthermore, a morphological analysis of the particle surfaces shows that PAHT caused no significant alteration (Figure 3(b)).
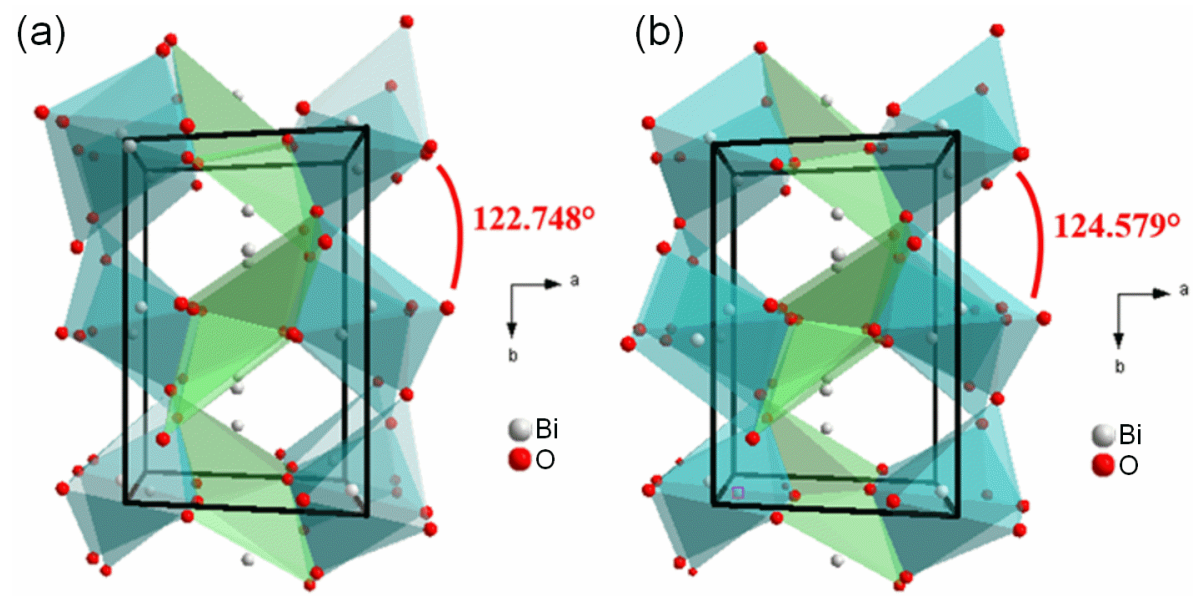

Figure 2. Coordination polyhedra for $\alpha-\mathrm{Bi}_{2} \mathrm{O}_{3}$ in the simulated structures. (a) $\alpha-\mathrm{Bi}_{2} \mathrm{O}_{3}-\mathrm{MAH}$, (b) $\alpha-\mathrm{Bi}_{2} \mathrm{O}_{3}-\mathrm{PAHT}$.

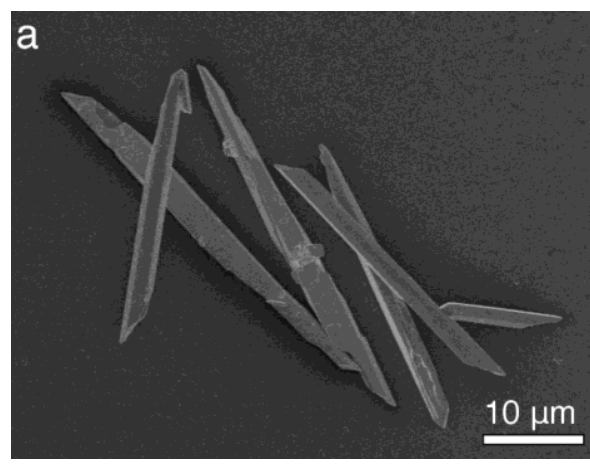

Figure 3. FESEM images

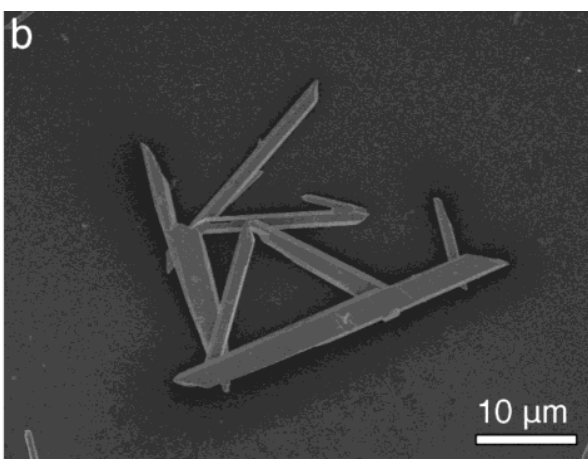

using secondary electrons. (a) $\quad \alpha-\mathrm{Bi}_{2} \mathrm{O}_{3}-\mathrm{MAH}$,

(b) $\alpha-\mathrm{Bi}_{2} \mathrm{O}_{3}-\mathrm{PAHT}$.

Figure 4 shows a comparison of the PL emission between $\alpha-\mathrm{Bi}_{2} \mathrm{O}_{3}-\mathrm{MAH}$ and $\alpha-\mathrm{Bi}_{2} \mathrm{O}_{3}-\mathrm{PAHT}$. The maximum PL emission occurred around $2.7 \mathrm{eV}$ (blue region) for both samples. After pressure treatment, a substantial increase in the PL intensity was observed. The PL bands were 
deconvoluted to evaluate which electronic transitions influence the PL response. The deconvolution of PL spectra is shown in Figure 5. The PL emission in both samples is composed of five components ranging between $1.77 \mathrm{eV}$ (red) and $3.05 \mathrm{eV}$ (violet), and were deconvoluted as $1.89,2.15,2.50,2.77$ and $3.05 \mathrm{eV}$, and $1.77,1.96,2.28,2.60$ and $2.85 \mathrm{eV}$ for $\alpha-\mathrm{Bi}_{2} \mathrm{O}_{3}-\mathrm{MAH}$ and $\alpha-\mathrm{Bi}_{2} \mathrm{O}_{3}-\mathrm{PAHT}$, respectively.

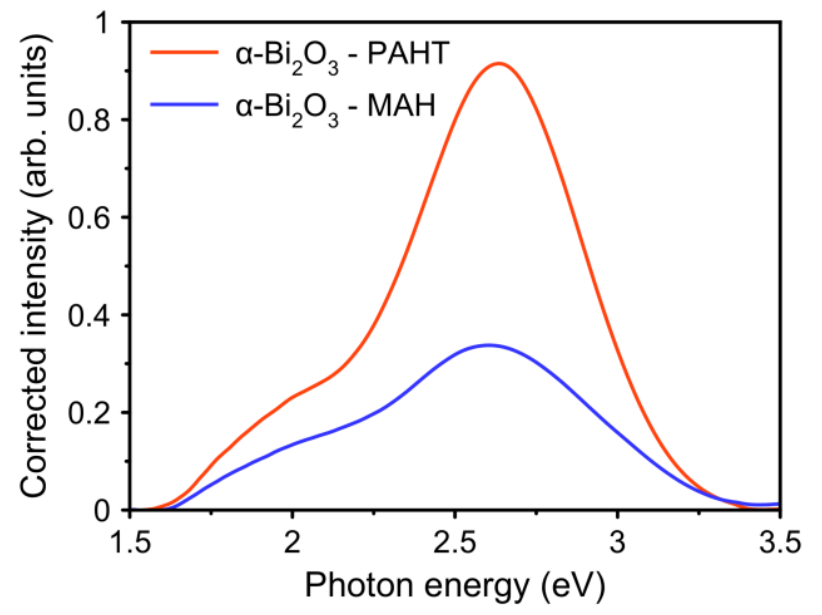

Figure 4. PL emission of $\alpha-\mathrm{Bi}_{2} \mathrm{O}_{3}-\mathrm{MAH}$ and $\alpha-\mathrm{Bi}_{2} \mathrm{O}_{3}-\mathrm{PAHT}$. 

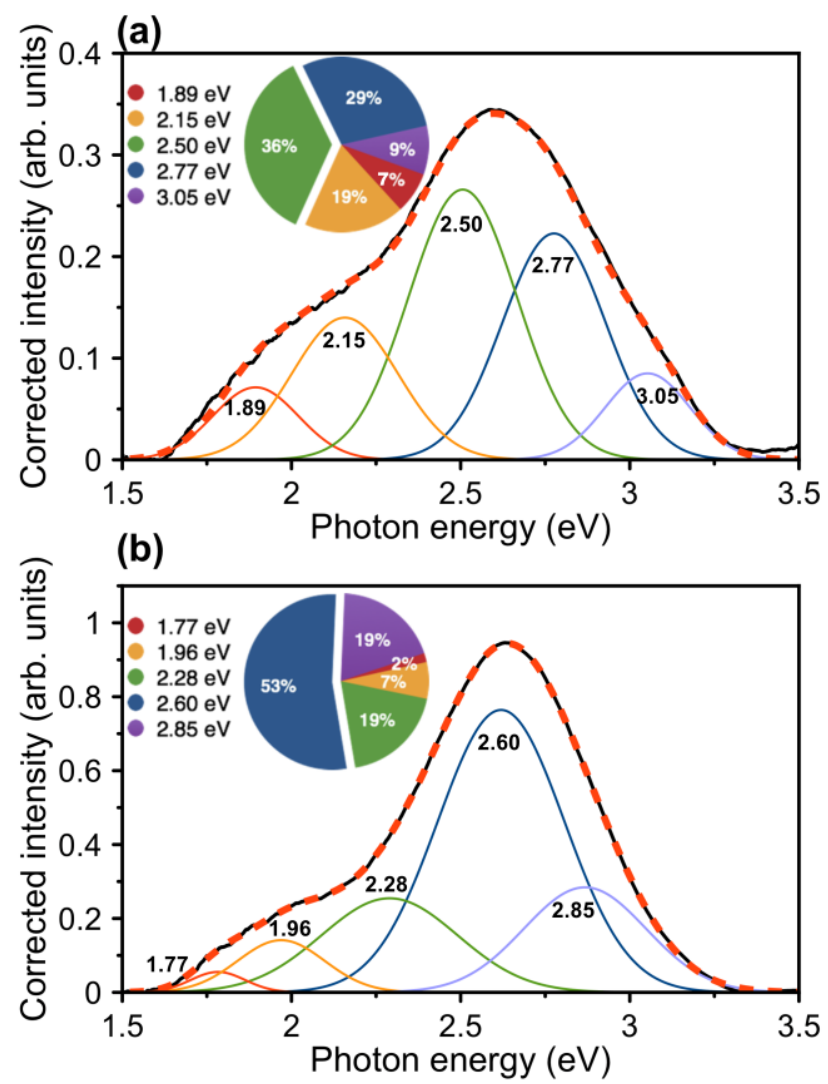

Figure 5. Deconvolution of PL spectra. (a) $\alpha-\mathrm{Bi}_{2} \mathrm{O}_{3}-\mathrm{MAH}$, (b) $\alpha-\mathrm{Bi}_{2} \mathrm{O}_{3}-\mathrm{PAHT}$. The dotted lines in (a) and (b) are the sum of the deconvolution peaks. $\mathrm{R}^{2}$ for both calculated fits is 0.998 .

Figure 6 shows the UV-vis absorption spectra of $\alpha-\mathrm{Bi}_{2} \mathrm{O}_{3}-\mathrm{MAH}$ and $\alpha-\mathrm{Bi}_{2} \mathrm{O}_{3}-\mathrm{PAHT}$, and an estimate of the band gap $\left(\mathrm{E}_{\mathrm{gap}}\right)$ for direct transitions, which was calculated using the KubelkaMunk ${ }^{25}$ method. The deconvolution shown in Figure 5 reveals that the PL emissions with the highest energy levels occurred around $3.05 \mathrm{eV}$ and $2.85 \mathrm{eV}$ (violet region) for $\alpha-\mathrm{Bi}_{2} \mathrm{O}_{3}-\mathrm{MAH}$ and $\alpha-\mathrm{Bi}_{2} \mathrm{O}_{3}-\mathrm{PAHT}$, respectively. These emissions can be related to the direct transitions between the conduction and valence bands since the band gap energies for both samples were estimated as 2.89 and $2.88 \mathrm{eV}$. These band gap values are close to those found in most literature reports $(2.85 \mathrm{eV})$ for $\alpha-\mathrm{Bi}_{2} \mathrm{O}_{3}$ structures. ${ }^{9-11}$ The band gap of $\alpha-\mathrm{Bi}_{2} \mathrm{O}_{3}-\mathrm{MAH}$ estimated by 
Kubelka-Munk is slightly lower than the corresponding value for the direct transitions found in PL deconvolution; other works ${ }^{6,11}$ reported a similar effect. Furthermore, PAHT promoted an increase in the contribution of the spectral range related to the direct transitions between the conduction and valence bands. Figure 5 shows that the contribution of this band changed from 9\% (3.05 eV) in $\alpha-\mathrm{Bi}_{2} \mathrm{O}_{3}-\mathrm{MAH}$ to $19 \%(2.85 \mathrm{eV})$ in $\alpha-\mathrm{Bi}_{2} \mathrm{O}_{3}-\mathrm{PAHT}$.

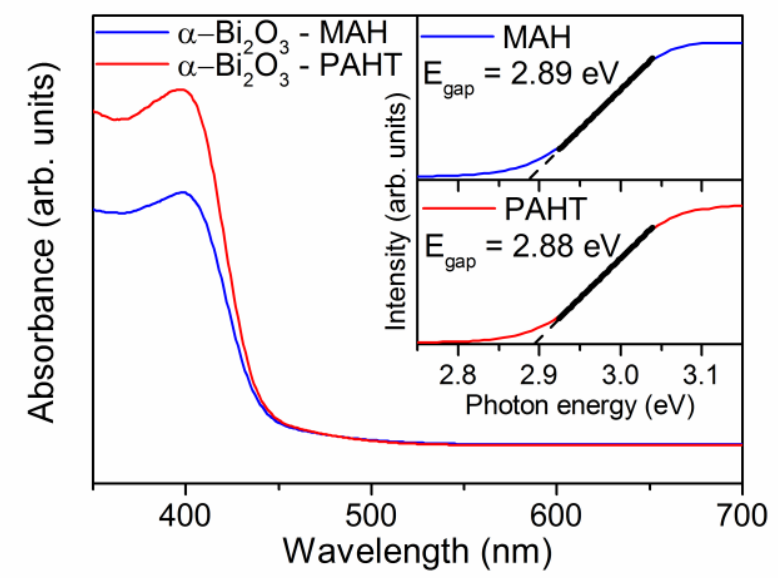

Figure 6. UV-vis absorption spectra and estimation of the band gap.

Trivalent bismuth ions in inorganic compounds exhibit PL properties related to their $6 \mathrm{~s}^{2}$ levels. The luminescence of $\mathrm{Bi}^{3+}$ ions appears in the blue-green region of the spectrum and is attributed to the ${ }^{3} \mathrm{P}_{1-}{ }^{1} \mathrm{~S}_{0}$ transitions or charge transfer between the bonding oxygen and $\mathrm{Bi}^{3+}$ ions. ${ }^{10-11,13}$ In $\alpha-\mathrm{Bi}_{2} \mathrm{O}_{3}-\mathrm{MAH}$, the bands associated with the blue-green emission corresponded to $65 \%$ of the total emission (29\% was attributed to the blue region $-2.77 \mathrm{eV}$ - while $36 \%$ was attributed to the green region $-2.50 \mathrm{eV}$ ). $\alpha-\mathrm{Bi}_{2} \mathrm{O}_{3}-\mathrm{PAHT}$ showed an increase in PL in the blue-green spectral range to $72 \%$, and an increase in the band relative to the blue component; in this case, $53 \%$ was related to the blue region $(2.60 \mathrm{eV})$ and $19 \%$ to the green region $(2.28 \mathrm{eV})$. 
Figures 4 and 5 also show PL emission in the low-energy region, and in this case, PAHT showed a significant decrease in the emission of this region related to the total PL emission. $\alpha$ $\mathrm{Bi}_{2} \mathrm{O}_{3}-\mathrm{MAH}$ has $19 \%$ of its emission at $2.15 \mathrm{eV}$ and $7 \%$ at $1.89 \mathrm{eV}$ that correspond to $26 \%$ of the total emission, while $\alpha-\mathrm{Bi}_{2} \mathrm{O}_{3}-\mathrm{PAHT}$ has $7 \%$ of its emission at $1.96 \mathrm{eV}$ and $2 \%$ at $1.77 \mathrm{eV}$, which correspond to only $9 \%$ of the total PL emission of $\alpha-\mathrm{Bi}_{2} \mathrm{O}_{3}-\mathrm{PAHT}$. The luminescence in the low-energy spectral range is normally attributed to the ${ }^{2} \mathrm{P}_{3 / 2}-{ }^{2} \mathrm{P}_{1 / 2}$ transition of $\mathrm{Bi}^{2+}$ ions. ${ }^{8,10}$ However, recent works ${ }^{11,30}$ reported that the emission in the low-energy spectral range is attributed to the structural defects of oxygen (oxygen vacancies). $\mathrm{Wu}$ and $\mathrm{Lu}^{30}$ also associated the PL emission at this spectral range to oxygen vacancies and stated that the higher the emission intensity at this spectral range the greater the vacancy density. Therefore, in order to determine the cause for the PL emission at this spectral range, it is necessary to verify the existence of $\mathrm{Bi}^{2+}$ ions on the material surface. In the present work, the presence or absence of $\mathrm{Bi}^{2+}$ ions in samples was tested using Raman and XPS spectra.

Raman characteristics of $\alpha-\mathrm{Bi}_{2} \mathrm{O}_{3}$ are well known. ${ }^{31}$ For the $\alpha-\mathrm{Bi}_{2} \mathrm{O}_{3}$ monoclinic structure with space group P21/c and 4 formula units or 20 atoms per unit cell, analyses predict 30 active Raman modes $(15 \mathrm{Ag}+15 \mathrm{Bg})$, but only a fraction of these modes is generally observed. ${ }^{11}$ The Raman spectra in Figure 7 show ten prominent Raman bands for both samples at 117, 138, 150, $183,210,284,313,410,445$, and $530 \mathrm{~cm}^{-1}$, which are in agreement with bands found in literature for $\alpha-\mathrm{Bi}_{2} \mathrm{O}_{3}{ }^{6,11,32}$ The band at $117 \mathrm{~cm}^{-1}$ is attributed to the vibration mode of bismuth while bands at 138 and $150 \mathrm{~cm}^{-1}$ refer to $\mathrm{Bi}-\mathrm{O}$ scattering. Furthermore, all other bands were attributed to oxygen vibrations, which are broader than bands observed at 117,138 , and $150 \mathrm{~cm}^{-}$ 1, and demonstrate a strong anharmonicity of oxygen vibration modes. Bands related to neither another $\mathrm{Bi}_{2} \mathrm{O}_{3}$ phase nor $\mathrm{Bi}^{2+}$ were detected for both $\alpha-\mathrm{Bi}_{2} \mathrm{O}_{3}-\mathrm{MAH}$ and $\alpha-\mathrm{Bi}_{2} \mathrm{O}_{3}-\mathrm{PAHT}$. 
A detailed comparison between the Raman spectra of $\alpha-\mathrm{Bi}_{2} \mathrm{O}_{3}-\mathrm{MAH}$ and $\alpha-\mathrm{Bi}_{2} \mathrm{O}_{3}-\mathrm{PAHT}$ in the low frequency range shows no relevant spectral changes. On the other hand, for frequencies higher than $284 \mathrm{~cm}^{-1}, \alpha-\mathrm{Bi}_{2} \mathrm{O}_{3}-\mathrm{PAHT}$ showed an increase in the spectrum intensity compared to $\alpha-\mathrm{Bi}_{2} \mathrm{O}_{3}-\mathrm{MAH}$. These different intensities can be associated to changes in the electronic density of the crystal, which also modifies the PL properties. The effect of intensity change in the Raman spectra has already been observed in other materials. For example, a change in the intensity of the Raman spectra was observed for $\mathrm{CaTiO}_{3}$ perovskite-based materials obtained by $\mathrm{MAH},{ }^{33}$ and for irregular cube-like $\left(\mathrm{Ca}_{1-\mathrm{x}} \mathrm{Cu}_{\mathrm{x}}\right) \mathrm{TiO}_{3}$ microcrystals also synthesized by MAH. ${ }^{34}$ In both studies, the authors showed that a change in the cluster angles promoted variations in intensities of the Raman spectra, which were attributed to changes in the average electronic density of the crystal, and could modify the PL properties. In addition, these authors used XRD and Rietveld refinements to measure the cluster angles in their samples. ${ }^{33-34}$ In the present work, the increase in Raman spectra intensity was caused by an increase in the average electronic density, which was promoted by the change in the angles between clusters $\left[\mathrm{BiO}_{6}\right]-\left[\mathrm{BiO}_{6}\right]$. Consequently, the intensity increase in the Raman spectra observed in $\alpha-\mathrm{Bi}_{2} \mathrm{O}_{3}-\mathrm{PAHT}$ is explained by a structural disorder caused by the increase in the relative angles between clusters $\left[\mathrm{BiO}_{6}\right]-\left[\mathrm{BiO}_{6}\right]$. Results of three experimental and theoretical studies ${ }^{35-37}$ on the structural properties of $\alpha-\mathrm{Bi}_{2} \mathrm{O}_{3}$ under high pressures, which also demonstrated that pressure promotes a distortion in clusters $\left[\mathrm{BiO}_{6}\right]-\left[\mathrm{BiO}_{6}\right]$, supports the results presented in this work.

The chemical states of the elements in the $\alpha-\mathrm{Bi}_{2} \mathrm{O}_{3}-\mathrm{MAH}$ and $\alpha-\mathrm{Bi}_{2} \mathrm{O}_{3}-\mathrm{PAHT}$ samples were also characterized by XPS, and Figure 8 depicts these results. Figures 8 (a) and (b) show the XPS spectra obtained for $\alpha-\mathrm{Bi}_{2} \mathrm{O}_{3}-\mathrm{MAH}$ and $\alpha-\mathrm{Bi}_{2} \mathrm{O}_{3}-\mathrm{PAHT}$, respectively. Figures $8(\mathrm{c})$ and (d) show the Bi4f levels, while Figures 8(e) and (f) show the O1s levels for both samples. 


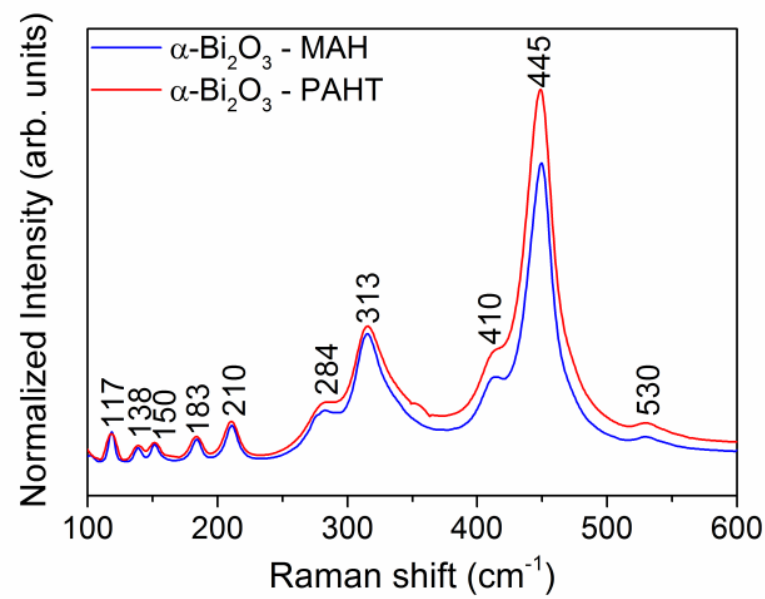

Figure 7. Raman spectra of $\alpha-\mathrm{Bi}_{2} \mathrm{O}_{3}-\mathrm{MAH}$ and $\alpha-\mathrm{Bi}_{2} \mathrm{O}_{3}-\mathrm{PAHT}$ samples.

XPS results indicated that the surfaces of both samples are composed of $\mathrm{Bi}_{2} \mathrm{O}_{3}$. Carbon peaks found in the XPS spectra (Figures 8(a) and (b)) can be attributed to contamination due to exposure to the atmosphere. ${ }^{38}$ Figure $8(\mathrm{c})$ and (d) present the spin orbit splitting for pure Bi4f $\mathrm{f}_{7 / 2}$ and $\mathrm{Bi}_{5 / 2}$ with binding energies of 159 and $164 \mathrm{eV}$, respectively. In addition, the spin orbit splitting with these binding energies values is a characteristic of $\mathrm{Bi}^{3+}$ ions in $\alpha-\mathrm{Bi}_{2} \mathrm{O}_{3} .{ }^{39}$

The XPS profiles of O1s levels, Figures 8(e) and (f), show a dominant peak at $529.7 \mathrm{eV}$, whose binding energy is a characteristic of oxygen in $\mathrm{Bi}_{2} \mathrm{O}_{3}$ (structural oxygen). The binding energy at $531 \mathrm{eV}$ could be attributed to the surface oxygen present as hydroxyl groups $\left(\mathrm{OH}^{-}\right) .{ }^{39-40}$ The hydroxyl groups could originate when the samples are exposed to air or could be adsorbed during the MAH synthesis in an alkaline medium.

Raman spectroscopy and XPS did not detect any signal indicating the presence of $\mathrm{Bi}^{2+}$ ions in $\alpha-\mathrm{Bi}_{2} \mathrm{O}_{3}-\mathrm{MAH}$ and $\alpha-\mathrm{Bi}_{2} \mathrm{O}_{3}-\mathrm{PAHT}$. These results suggests the PL emission in the low energy region (below about $2.1 \mathrm{eV}$ ) is due to oxygen vacancies that form defect donor states, and this PL comprises a lot of defect donor states to valence band emissions. ${ }^{3}$ The oxygen vacancy states 
may contain centers of bismuth in other oxidation states, including $\mathrm{Bi}^{2+}$, which can emit PL from red to blue emission. ${ }^{41}$ The present work shows that emission in the low energy region (below about $2.1 \mathrm{eV}$ ) can be attributed to oxygen vacancies that were coherently reduced after PAHT. These results are in good agreement with reports from literature that states the PL emission at this region is explained in terms of oxygen defects and bismuth oxidation states. ${ }^{6,11,14}$ However, XPS results presented in the work of Vila et. al. ${ }^{6}$ showed the presence $\mathrm{Bi}^{2+}$ on sample surface while in the present work Raman and XPS results showed no signal of $\mathrm{Bi}^{2+}$.
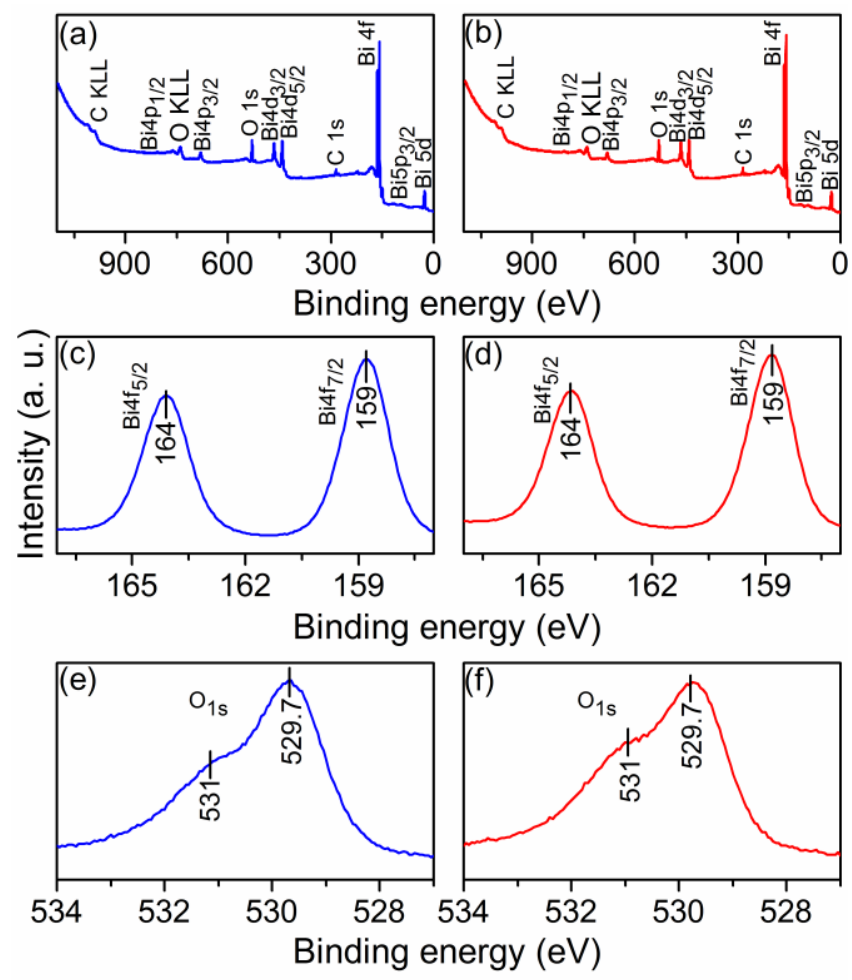

Figure 8. XPS spectra of samples (a) $\alpha-\mathrm{Bi}_{2} \mathrm{O}_{3}-\mathrm{MAH}$ and (b) $\alpha-\mathrm{Bi}_{2} \mathrm{O}_{3}-\mathrm{PAHT}$. XPS spectra of $\mathrm{Bi}_{4} \mathrm{f}_{7 / 2}$ and $\mathrm{Bi} 4 \mathrm{f}_{5 / 2}$ levels for (c) $\alpha-\mathrm{Bi}_{2} \mathrm{O}_{3}-\mathrm{MAH}$ and (d) $\alpha-\mathrm{Bi}_{2} \mathrm{O}_{3}-\mathrm{PAHT}$. XPS spectra of O1s levels for (e) $\alpha-\mathrm{Bi}_{2} \mathrm{O}_{3}-\mathrm{MAH}$ and (f) $\alpha-\mathrm{Bi}_{2} \mathrm{O}_{3}-\mathrm{PAHT}$. 
The calculated bulk $\mathrm{Bi}_{2} \mathrm{O}_{3}$ band structures along the adequate symmetry lines of the monoclinic $C 2 / m$ Bravais lattice and the density of states (DOS) total and projected on most relevant atomic orbitals for the two $\mathrm{Bi}_{2} \mathrm{O}_{3}$ samples are shown in Figure 9. Our theoretical calculations render for the $\alpha-\mathrm{Bi}_{2} \mathrm{O}_{3}-\mathrm{MAH}$ structure that the valence band (VB) maximum and conduction band (CB) minimum are located at $\mathrm{Z}$ and near $\Gamma$ (actually in the line between $\Gamma$ and $\mathrm{Y}$ but close to $\Gamma$ ) $k$-points. The calculated band gap is $2.149 \mathrm{eV}$ close to the direct band gap at $\Gamma$ of $2.194 \mathrm{eV}$. The $\alpha-\mathrm{Bi}_{2} \mathrm{O}_{3}-\mathrm{PAHT}$ band structure presents also an indirect gap of $1.919 \mathrm{eV}$ from $\Gamma$ vicinity to a point between $\Gamma$ and $\mathrm{B} k$-points also close to the direct gap at $\Gamma$ of $2.059 \mathrm{eV}$.
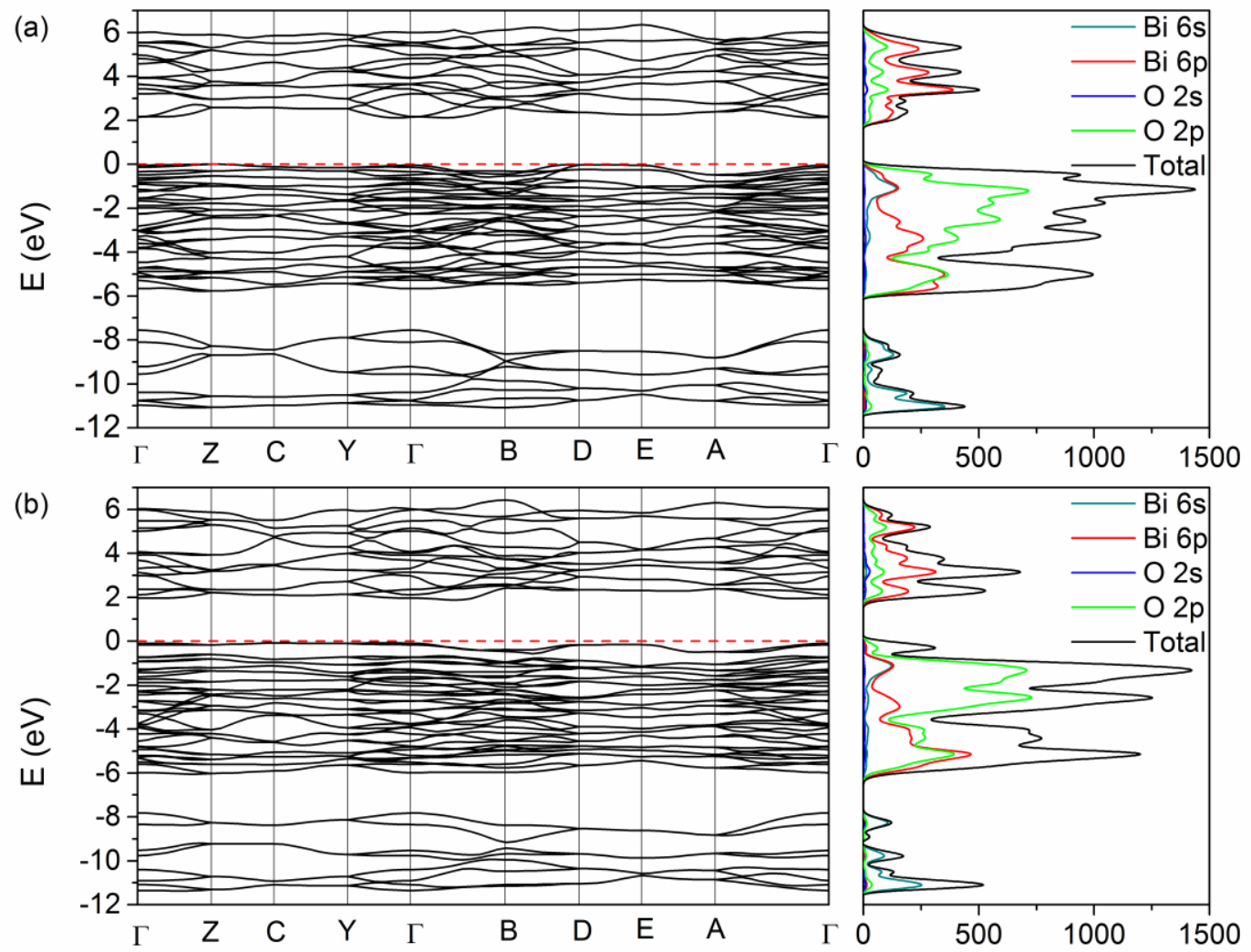

Figure 9. Electronic band structures and partial electron density of states for (a) $\alpha-\mathrm{Bi}_{2} \mathrm{O}_{3}-\mathrm{MAH}$ (ambient pressure) and (b) $\alpha-\mathrm{Bi}_{2} \mathrm{O}_{3}-\mathrm{PAHT}$ (2 MPa pressure). The top of the valence band is set to 0 on the vertical axis 
It is well known that Local Density (LDA) and Generalized Gradient Approximation (GGA) density functionals generally underestimate band gaps for semiconductors. Taken this fact into account our results compare well with the calculated indirect band gap of $2.45 \mathrm{eV}$ at ambient pressure using GGA-PBE ${ }^{42}$ method and with and the experimental value of $2.5 \mathrm{eV}^{43}$ and with our experimental value of $2.88-2.89 \mathrm{eV}$. Our calculations predict for both $\alpha-\mathrm{Bi}_{2} \mathrm{O}_{3}-\mathrm{MAH}$ and $\alpha-$ $\mathrm{Bi}_{2} \mathrm{O}_{3}-\mathrm{PAHT}$ structures that the top of VB is derived mostly from $\mathrm{O} 2 p$ and in less measure from the Bi $6 p$ and $6 s$ states, suggesting a slight hybridization of the $\mathrm{Bi} 6 s$ and $\mathrm{Bi} 6 p$ orbitals, while in the bottom of $\mathrm{CB}$ the $\mathrm{Bi} 6 p$ dominate over the $\mathrm{O} 2 p$ contribution states. Therefore, photoelectron mainly transfers from $\mathrm{O} 2 p$ and $\mathrm{Bi} 6 s-6 p$ in the top of $\mathrm{VB}$ to $\mathrm{Bi} 6 p$ in the bottom of $\mathrm{CB}$. The decrease in the $\alpha-\mathrm{Bi}_{2} \mathrm{O}_{3}-\mathrm{PAHT}$ band gap energy is due to an increase of the Fermi energy and a slight decrease of its CB minimum.

Upon comparing the PL emission of $\alpha-\mathrm{Bi}_{2} \mathrm{O}_{3}-\mathrm{MAH}$ and $\alpha-\mathrm{Bi}_{2} \mathrm{O}_{3}-\mathrm{PAHT}$ (Figure 4), the latter showed an increase in the PL intensity. The pressure-assisted heat treatment of $\alpha-\mathrm{Bi}_{2} \mathrm{O}_{3}-\mathrm{MAH}$ needles caused an increase in the angle between $\left[\mathrm{BiO}_{6}\right]-\left[\mathrm{BiO}_{6}\right]$ clusters, which promoted a rise in the electronic density of the material, which was considered as the cause for the increase in PL emission intensity. On the other hand, the contribution of PL emission in the low-energy range to the total PL emission is considerably greater in $\alpha-\mathrm{Bi}_{2} \mathrm{O}_{3}-\mathrm{MAH}$ than in $\alpha-\mathrm{Bi}_{2} \mathrm{O}_{3}-\mathrm{PAHT}$. This is mainly because $\alpha-\mathrm{Bi}_{2} \mathrm{O}_{3}-\mathrm{PAHT}$ suffered the pressure-assisted heat treatment under air atmosphere (rich in oxygen). Consequently, under higher oxygen pressure, the formation of oxygen vacancies that form the defect donor states was in disadvantage.

Theoretical results showed that $\mathrm{O} 2 p$ states have an important role in photoelectron transfers in both samples. For both $\alpha-\mathrm{Bi}_{2} \mathrm{O}_{3}-\mathrm{MAH}$ and $\alpha-\mathrm{Bi}_{2} \mathrm{O}_{3}-\mathrm{PAHT}$, the top of $\mathrm{VB}$ is mainly composed of O $2 p$ states, which are predominantly influenced by changes on axial oxygen atoms of [ $\left.\mathrm{BiO}_{6}\right]$ 
octahedra. The axial oxygen atoms are directly involved in the angles between $\left[\mathrm{BiO}_{6}\right]-\left[\mathrm{BiO}_{6}\right]$ clusters that were greater in $\alpha-\mathrm{Bi}_{2} \mathrm{O}_{3}-\mathrm{PAHT}$ than in $\alpha-\mathrm{Bi}_{2} \mathrm{O}_{3}-\mathrm{MAH}$. Rietveld refinements already showed the difference in cluster angles of samples (Figure 2). In addition, the change in cluster angle can directly change the polarization of $\mathrm{O} 2 p$ states, and, consequently, their interaction with $\mathrm{Bi} 6 p$ states. As a result, the change in the angles between $\left[\mathrm{BiO}_{6}\right]-\left[\mathrm{BiO}_{6}\right]$ clusters promote an increase in the electronic density of crystal and the increase in the PL intensity. These findings are in good agreement with the discussion on Raman spectra (Figure 7), that shows an increase in the electronic density of $\alpha-\mathrm{Bi}_{2} \mathrm{O}_{3}-\mathrm{PAHT}$.

\section{CONCLUSIONS}

The pressure-assisted heat treatment of $\alpha-\mathrm{Bi}_{2} \mathrm{O}_{3}-\mathrm{MAH}$ needles caused an intrinsic disorder characterized by an increase in the angle between the $\left[\mathrm{BiO}_{6}\right]-\left[\mathrm{BiO}_{6}\right]$ clusters. This angular increase promoted a significant rise in the electronic density of the material, which was considered as the cause for the increase in PL emission intensity in the blue region. Consequently, the origin of the structure with higher electronic density and the increase in PL emission intensity are due to the structural distortion related to the $\left[\mathrm{BiO}_{6}\right]-\left[\mathrm{BiO}_{6}\right]$ clusters. In addition, the PL emissions of $\alpha-\mathrm{Bi}_{2} \mathrm{O}_{3}$ in the low-energy region (below about $2.1 \mathrm{eV}$ ) can be attributed to oxygen defects (oxygen vacancies) that form defect donor states; this PL comprises defect states to valence band emissions. Theoretical calculation is in good agreement with the experimental findings. Theoretical results showed that $\mathrm{O} 2 p$ states have an important role in photoelectron transfers in both samples. The change in the angle between the $\left[\mathrm{BiO}_{6}\right]-\left[\mathrm{BiO}_{6}\right]$ clusters can change the polarization of $\mathrm{O} 2 p$ states, and, consequently, change the electronic density of crystals. 


\section{ASSOCIATED CONTENT}

\section{Supporting Information}

CIF generated at the end of Rietveld refinements using the Topas Academic v. 5 software to simulate the coordination polyhedra and deconvolution of XPS spectra. This material is available free of charge via the Internet at http://pubs.acs.org.

\section{AUTHOR INFORMATION}

\section{Corresponding Author}

*E-mail: varela@iq.unesp.br. Phone:+55 16 3301-9892

\section{Notes}

The authors declare no competing financial interest.

\section{ACKNOWLEDGMENTS}

This research was funded by The State of Sao Paulo Research Foundation (FAPESP), Research Award CEPID 2013/07296-2. The author S. Schmidt is also grateful to the Coordination for the Improvement of Higher Education Personnel (Capes) for her doctoral scholarship. This work was also supported by Spanish MALTA-Consolider Ingenio 2010 Program (Project CSD2007-00045). Authors are also grateful to Prof. Juan Andrés for his collaboration in the preparation of this article. 


\section{REFERENCES}

(1) Ismail, R. A.; Fadhil, F. A. J. Mater. Sci.: Mater. Electron. 2014, 25, 1435-1440.

(2) Yang, G. B.; Li, Y. X.; Yin, Q. R.; Wang, P. L.; Cheng, Y. B. Mater. Lett. 2002, 55, 46-49.

(3) Ho, C. H.; Chan, C. H.; Huang, Y. S.; Tien, L. C.; Chao, L. C. Opt. Express 2013, 21, 11965-11972.

(4) Harwig, H. A.; Gerards, A. G. Thermochim. Acta 1979, 28, 121-131.

(5) Huang, L.; Li, G.; Yan, T.; Zheng, J.; Li, L. New J. Chem. 2011, 35, 197-203.

(6) Vila, M.; Diaz-Guerra, C.; Piqueras, J. J. Alloys Compd. 2013, 548, 188-193.

(7) Rietveld, H. J. Appl. Crystallogr. 1969, 2, 65-71.

(8) Tien, L.-C.; Lai, Y.-C. Appl. Surf. Sci. 2014, 290, 131-136.

(9) Xiong, Y.; Wu, M.; Ye, J.; Chen, Q. Mater. Lett. 2008, 62, 1165-1168.

(10) Wang, Y.; Zhao, J.; Zhou, B.; Zhao, X.; Wang, Z.; Zhu, Y. J. Alloys Compd. 2014, 592, 296-300.

(11) Vila, M.; Diaz-Guerra, C.; Piqueras, J. Mater. Chem. Phys. 2012, 133, 559-564.

(12) Bordun, O. M.; Kukharskii, I. I.; Dmitruk, V. V.; Antonyuk, V. G.; Savchin, V. P. J Appl Spectrosc 2008, 75, 681-684.

(13) Boutinaud, P. Inorg. Chem. 2013, 52, 6028-6038. 
(14) Vila, M.; Diaz-Guerra, C.; Piqueras, J.; Lopez-Conesa, L.; Estrade, S.; Peiro, F. CrystEngComm 2015, 17, 132-139.

(15) Sequinel, T.; Garcia, I. G.; Tebcherani, S. M.; Kubaski, E. T.; Oliveira, L. H.; Li, M. S.; Longo, E.; Varela, J. A. J. Alloys Compd. 2014, 583, 488-491.

(16) Berger, D.; Kubaski, E. T.; Sequinel, T.; da Silva, R. M.; Tebcherani, S. M.; Varela, J. A. Luminescence 2013, 28, 942-947.

(17) Coelho, A. Topas Academic, version 5; Coelho Software: Brisbane, 2012.

(18) Cheary, R.; Coelho, A.; JP, C. J. Res. Natl. Inst. Stand. Technol. 2004, 109, 1-25.

(19) Malmros, G. Acta Chem. Scand. 1970, 24, 384-396.

(20) Putz, H.; Brandenburg, K. Diamond - Crystal and Molecular Structure Visualization, version 3.2; Crystal Impact: Bonn, 2010.

(21) Rodríguez-Carvajal, J. Phys. B (Amsterdam, Neth.) 1993, 192, 55-69.

(22) Hamilton, T. D. S.; Munro, I. H.; Walker, G. Luminescence Instrumentation. In Luminescence Spectroscopy, Lumb, M. D., Ed. Academic Press: London, 1978; pp 149-238.

(23) Kalceff, M. A. S.; Phillips, M. R. Phys. Rev. B: Condens. Matter Mater. Phys. 1995, 52, 3122-3134.

(24) PeakFit, version 4.12; Systat Software Inc.

(25) Kubelka, P.; Munk-Aussig, F. Z. Tech. Physik 1931, 12, 593-601. 
(26) Shirley, D. A. Phys. Rev. B: Condens. Matter Mater. Phys. 1972, 5, 4709-4714.

(27) Dovesi, R.; Saunders, V. R.; Roetti, C.; Orlando, R.; Zicovich-Wilson, C. M.; F. Pascale, B. C.; Doll, K.; Harrison, N. M.; Bush, I. J.; D’Arco, P.; Llunell, M.; Causà, M.; Noël, Y. CRYSTAL14 User's Manual (University of Torino, Torino 2014). 2014.

(28) Perdew, J. P.; Ruzsinszky, A.; Csonka, G. I.; Vydrov, O. A.; Scuseria, G. E.; Constantin, L. A.; Zhou, X.; Burke, K. Phys. Rev. Lett. 2008, 100, 136406.

(29) Young, R. A. The Rietveld Method. 1 ed.; Oxford University Press: New York, 1993.

(30) Wu, Y.; Lu, G. Phys. Chem. Chem. Phys. 2014, 16, 4165-4175.

(31) Wang, Y.; Zhao, J.; Zhu, Y.; Zhou, B.; Zhao, X.; Wang, Z. Colloids Surf., A 2013, 434, 296-302.

(32) Yuvakkumar, R.; Hong, S. I. Spectrochim. Acta, Part A 2015, 144, 281-286.

(33) Moreira, M. L.; Paris, E. C.; do Nascimento, G. S.; Longo, V. M.; Sambrano, J. R.; Mastelaro, V. R.; Bernardi, M. I. B.; Andrés, J.; Varela, J. A.; Longo, E. Acta Mater. 2009, 57, $5174-5185$.

(34) Oliveira, L. H.; de Moura, A. P.; Mazzo, T. M.; Ramírez, M. A.; Cavalcante, L. S.; Antonio, S. G.; Avansi, W.; Mastelaro, V. R.; Longo, E.; Varela, J. A. Mater. Chem. Phys. 2012, $136,130-139$.

(35) Ghedia, S.; Locherer, T.; Dinnebier, R.; Prasad, D. L. V. K.; Wedig, U.; Jansen, M.; Senyshyn, A. Phys. Rev. B: Condens. Matter Mater. Phys. 2010, 82, 024106. 
(36) Locherer, T.; Prasad, D. L. V. K.; Dinnebier, R.; Wedig, U.; Jansen, M.; Garbarino, G.;

Hansen, T. Phys. Rev. B: Condens. Matter Mater. Phys. 2011, 83, 214102.

(37) Pereira, A.; Errandonea, D.; Beltrán, A.; Gracia, L.; Gomis, O.; Sans, J.; García-Domene, B.; Miquel-Veyrat, A.; Manjón, F.; Muñoz, A.; Popescu, C. J. Phys.: Condens. Matter 2013, 25, 475402.

(38) Sarma, B.; Jurovitzki, A. L.; Smith, Y. R.; Mohanty, S. K.; Misra, M. ACS Appl. Mater. Interfaces 2013, 5, 1688-1697.

(39) Jiang, H.-Y.; Jingjing, L.; Kun, C.; Wenbin, S.; Jun, L. J. Phys. Chem. C 2013, 117, 20029-20036.

(40) Myung, N.; Sunyoung, H.; Seungun, C.; Yujin, C.; Whan-Gi, K.; Jin, J. Y.; Ki-Jung, P.;

Wilaiwan, C.; R., d. T. N.; Krishnan, R. J. Phys. Chem. C 2011, 115, 7793-7800.

(41) Zhou, S.; Jiang, N.; Zhu, B.; Yang, H.; Ye, S.; Lakshminarayana, G.; Hao, J.; Qiu, J. Adv. Funct. Mater. 2008, 18, 1407-1413.

(42) Lei, Y.-H.; Chen, Z.-X. J. Chem. Phys. 2013, 138, 054703.

(43) Debies, T. P.; Rabalais, J. W. Chem. Phys. 1977, 20, 277-283. 


\section{FOR TABLE OF CONTENTS ONLY}

Synopsis

The pressure-assisted heat treatment of $\alpha-\mathrm{Bi}_{2} \mathrm{O}_{3}$ with a needle morphology synthesized using the microwave-assisted hydrothermal method caused an angular increase between the $\left[\mathrm{BiO}_{6}\right]-\left[\mathrm{BiO}_{6}\right]$ clusters of $\alpha-\mathrm{Bi}_{2} \mathrm{O}_{3}$, resulting in changes in average electronic density of the crystal and in a significant rise in the PL emission intensity. The $\alpha-\mathrm{Bi}_{2} \mathrm{O}_{3} \mathrm{PL}$ emissions in the low-energy region are attributed to oxygen defects (oxygen vacancies) that form defect donor states; this PL comprises defect states to valence band emissions.

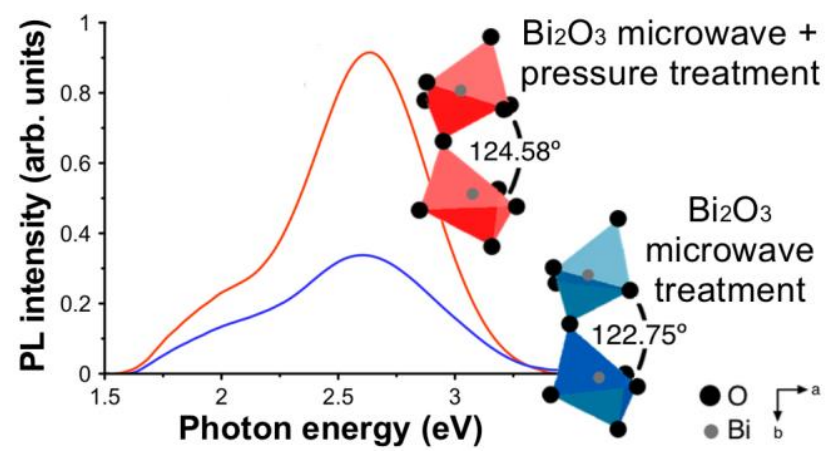

